\title{
Assessing the eHealth literacy skills of family caregivers of medically ill elderly
}

\author{
Ali Soleimaninejad ${ }^{1}$, Saeideh Valizadeh-Haghi ${ }^{2 *}$, Shahabedin Rahmatizadeh ${ }^{3}$ \\ ${ }^{1}$ Student Research Committee, Faculty of Public Health and Safety, Shahid Beheshti University of Medical \\ Sciences, Tehran, Iran. \\ ${ }^{2}$ Department of Medical Library and Information Sciences, School of Allied Medical Sciences, Shahid \\ Beheshti University of Medical Sciences, Tehran, Iran. \\ ${ }^{3}$ Department of Health Information Technology and Management, School of Allied Medical Sciences, \\ Shahid Beheshti University of Medical Sciences, Tehran, Iran.
}

\begin{abstract}
Objectives: The purpose of current research is to assess the eHealth literacy level in the family caregivers of the elderly with hypertension and type-II diabetes.

Methods: A total of 160 caregivers completed the eHEALS questionnaire. The effect of participants' gender, education, and age on eHealth literacy was evaluated. For evaluation of the correlation between the accession of health information importance and the internet usefulness for decision-making, Spearman's correlation coefficient was applied.

Results: The participants eHealth literacy mean score was $26.163(S D=8.83)$. The age of participants had a meaningful impact on the level of eHealth literacy $(t=6.074 ; P<0.001)$. Furthermore, among variant education levels in terms of eHealth literacy score significant differences existed $(F=5.222 ; P=0.001)$.

Discussion: The family caregivers have a poor level of eHealth literacy. eHealth information is more important for family caregivers with a higher eHealth literacy, which may be due to their higher skills in obtaining health and medical information from the internet. Caregivers' age should be considered once recommending them for the internet using to obtain health information, as the age was an affecting factor.

Conclusion: Health centers and authorities in charge of the elderly health are recommended to train caregivers with proper skills to use online health information, such that the elderly enjoy the benefits, including improved care conditions and savings in terms of treatment costs and time.

Keywords: eHealth literacy; Family Caregivers; Online health information; Consumer health information; Patient education, eHealth, Health information, Elderly, Aged

Abbreviations: electronic health (eHealth)

*Correspondence: Saeideh Valizadeh-Haghi, email: Saeideh.valizadeh@gmail.com

DOI: 10.5210/ojphi.v11i2.10149
\end{abstract}


Copyright (02019 the author(s)

This is an Open Access article. Authors own copyright of their articles appearing in the Online Journal of Public Health Informatics. Readers may copy articles without permission of the copyright owner(s), as long as the author and OJPHI are acknowledged in the copy and the copy is used for educational, not-for-profit purposes.

\section{Introduction}

The dramatic increase in the world's elderly population and occurrence of chronic debilitating diseases such as hypertension [1] and diabetes [2] among others have forced the elderly to use nursing care and become homebound $[3,4]$ and have made the care requirements of this population group inevitable. Diabetes and hypertension are two major risk factors for cardiovascular diseases in the elderly and adult population [5,6]. Due to their chronic and debilitating nature and since they require lifelong care, these diseases badly affect the patients' quality of life [7]. Moreover, the family assumes an important part of the responsibility of elderly care, including the continued intake of medications, the interpretation of medical information, following up on future visits, visiting specialists regarding their health issues and making decisions about using health services $[8,9]$. In fact, families assume more than $80 \%$ of the responsibility for any care the elderly need [10]. The main reasons for the emergence of the phenomenon of family care include the increase in the elderly population and their affliction with chronic diseases, changes in the health system, especially regarding the health of family caregivers, and the rising costs of hospitalization. Nevertheless, families are faced with challenges in providing services and taking care of the elderly at home. Researches conducted on the family caregivers of the elderly mostly confirm that promoting caregivers' knowledge and information and increasing their understanding of old-agerelated problems and the optimal ways of dealing with them reduce caregivers' occupational stress and increase their motivation to provide the elderly with quality services [11]. One of the ways for training caregivers is through electronic technologies and the internet. The internet is one of the information sources used by caregivers to obtain health information. The health information available on the internet can have a major role in caregivers' decision-making about the provision of better care services to the elderly. Moreover, using the health information obtained from this medium improves caregivers' mental health [12] and can be effective in the process of elderly's treatment and help family caregivers better manage their provision of health and medical services to the elderly. Caregivers' internet access and use seem to be affected by demographic and socioeconomic factors. In particular, the likelihood of using health information available on the internet is increased in young and educated caregivers with a higher income who spend less time on caregiving [13]. An important point about obtaining information through the internet is that inadequate skills in searching for and understanding health information impede optimal access to online/electronic information or lead to their inappropriate use [14]. The proper use of the internet requires the ability to read, use the computer, search for information and understand and utilize the health information gathered [15]. What matters in the use of electronic health information sources is Electronic Health Literacy (eHealth literacy), which has been characterized as "The individual's ability to search, find, understand and evaluate health information from electronic sources and use this knowledge to solve health problems" [14,16]and includes computer literacy, information literacy, media literacy, health literacy, traditional literacy and scientific literacy [17]. Electronic Health literacy can help establish better communication between service providers and 
patients and facilitates the access to health and medical care [18]and ultimately improves individuals' health $[19,20]$.

According to various studies, people with inadequate skills to search for eHealth information will have difficulty in evaluating the quality of such information [21,22]. The health information provided by health websites are of different reliability and quality [23-25] and people have different abilities in understanding the reliability of web-based health information and properly using such information [26,27]. Therefore, attention to people's eHealth literacy is highly important, because the health information available on the internet can affect people's self-care and health-related decisions and lead to doctor visits or the seeking of consultation about health matters in 12\%-14\% of the cases [28,29]. As a result, proper understanding of people's capability to identify and correctly usage of credible online information is mandatory by heath specialists. To do so, prior to advising their patients to obtain health information on the internet, the eHealth literacy of the patients should be evaluated.

In Asian countries, including Iran, family caregivers have a major share of the care provided to the elderly. In line with other countries, Iran is also experiencing a growing phenomenon of aging [30]. According to Iranian beliefs, caring for the elderly is a sacred endeavor [31]. An estimated $80 \%$ of the patients with chronic diseases are cared for at home only by a family member, friend or relative [32]. Diabetes and hypertension are among the most common diseases of old age. Cardiovascular complications are the most common causes of death in the elderly, and this rate increases as blood pressure rises [33,34]. Given caregivers' need for information about elderly's diseases and the use of the internet as a source of information [35], it is important to understand the level of family caregivers' eHealth literacy and its contributing factors. Nevertheless, in this age of modern technologies, there seems to be a research gap between caregivers' eHealth literacy and their skills. Thus, the current research was performed to (A) Determine the level of eHealth literacy in the family caregivers of the elderly with hypertension and type-II diabetes, and (B) Assess the importance and usefulness of access to eHealth information in view of family caregivers and determine the factors affecting the level of eHealth literacy in this population group.

\section{Methods}

In the present cross-sectional study, the family caregivers of the elderly covered by the health base of Varamin were selected from April to June 2018 through purposive sampling. The city of Varamin is the administrative center of Varamin township in Tehran Province located in the southeast of Tehran city and has a population of about 225000. Varamin health center is responsible for providing the residents of this city with all types of primary health services. To conduct this research, first, all the elderly with hypertension and type-II diabetes visiting this center for receiving health and medical services were assessed in terms of having a family caregiver. Then, all their family caregivers were assessed in terms of meeting the standards of: living with the elderly, their familiarity with the internet, willingness to take part and absence of severe physical deficiencies (blindness, deafness and other physical or mental disabilities. A total of 160 caregivers (aged 18 to 60 years) were eligible and selected as the study subjects in the study.

Many researchers divide adults into three age ranges, including young adults (under 40), middle adults (over 40) and older adults (over 65) [36]. Thus, regarding the participants`age range in this 
study (aged 18 to 60 years), they were divided by age into two groups including middle adults (over 40 years old) and young adults (below 40 years old).

\section{Data collection tools}

Data were collected using the eHealth Literacy Scale (eHEALS), which measures the individual's skills and confidence in the internet using to gather health-related information [15]. The eHEALS comprises 8 items scored according to the 5-point Likert scale (from 'completely disagree' $=1$ to 'completely agree' =5), with the range of total score from eight to 40 and greater scores representing a eHealth literacy higher level [15]. The "importance of access to the health information available on the internet" and "the usefulness of the internet in health decisionmaking" are two supplementary items of eHEALS scale which are designed to assess the participants' general interest in using eHealth information. These items are scored based on a 5point Likert scale (from 'totally useless' $=1$ to 'totally useful' $=5$ ), with the total score ranging from 2 to 10 [15]. The eHEALS internal consistency was evaluated and approved with 0.82 Cronbach's alpha, that agrees with other studies were reported [15,37,38]. The researchers distributed the eHEALS questionnaire in printed format among the research population. To observe the ethical principles, all the questionnaires were anonymous, and informed consent was acquired from all the participants, who were also ensured of the confidentiality of the data and the researchers' compliance with ethical principles. Current research has been approved by ethics committee of SBMU (ethics code: IR.SBMU.RETECH.REC.1397.389)

\section{Data analysis}

The data analysis was performed using SPSS-18. The effect of participants' gender, education, and age on eHealth literacy was evaluated. By absolute and relative frequencies, the qualitative variables were defined and by the standard deviation and mean the quantitative variables were described. The eHealth literacy mean scores were compared with gender and age by the independent t-test and with education by the ANOVA. The association of "Usefulness of the internet for decision-making", "The importance of access to eHealth information", "Ability to differentiate between quality and reliable online health information resources and poor-quality and unreliable ones", and "Adequate self-confidence in using online information for medical and health decision-making" with gender and age was measured by Mann-Whitney's test and with education was measured by the Kruskal-Wallis test. The Spearman correlation coefficient was applied for evaluation of the correlation between importance of access to health information and the usefulness of the internet for decision-making. In all tests, a significant level of 0.05 was considered. Data were described using mean, standard deviation and frequency indices.

\section{Results:}

The majority $(61.9 \%)$ of the participants were female, and only $22.5 \%$ had a different level of education at the university. Most of these family caregivers (66.3\%) were younger than 40 years (Table 1). 
Table 1: Demographic characteristics of study participants $(n=160)$

\begin{tabular}{ccc}
\hline Demographics & & $\mathbf{N}(\boldsymbol{\%})$ \\
\hline Gender & Female & $99(61.9)$ \\
& Male & $61(38.1)$ \\
\hline Education & High school dropout & $71(44.4)$ \\
& High school graduate & $53(33.1)$ \\
& Associates degree & $18(11.3)$ \\
& Bachelor's degree & $16(10.0)$ \\
& Master's degree & $2(1.2)$ \\
\hline Age group & $18-40$ & $106(66.3)$ \\
& $>40$ & $54(33.8)$ \\
\hline
\end{tabular}

Participants' mean score of eHealth literacy was 26.163 (SD=8.83). Given that the maximum attainable score in this questionnaire is 40 , this finding shows that the family caregivers had a poor level of eHealth literacy. In the present study, the question "I am able to differentiate quality and reliable health information sources from poor-quality and unreliable internet sources" obtained the lowest score (3.138 \pm 1.130$)$, which shows that participants' biggest problem was differentiating quality sources from poor-quality ones (Table 2). The eHealth literacy level was also measured by gender. The findings showed that although the female caregivers had higher eHealth literacy scores (26.81 \pm 8.96$)$ compared to the male caregivers $(25.09 \pm 8.56)$, this difference was not statistically significant according to the independent $\mathrm{t}$-test $(\mathrm{t}=1.198 ; \mathrm{P}=0.233)$.

Table 2: The mean and standard deviation of the score of each item of eHEALS

\begin{tabular}{lccc}
\hline \multicolumn{1}{c}{ eHealth Literacy Scale } & Mean & SD & Median \\
\hline I know what health resources are available on the Internet & 3.394 & 1.122 & 4 \\
I know where to find helpful health resources on the Internet & 3.231 & 1.011 & 3 \\
I know how to find helpful health resources on the Internet & 3.181 & 1.069 & 3 \\
I know how to use the Internet to answer my questions about health & 3.250 & 1.076 & 4 \\
I know how to use the health information I find on the Internet to help me & 3.188 & 1.065 & 3 \\
I have the skills I need to evaluate the health resources I find on the Internet & 3.194 & 1.067 & 3 \\
I can tell high quality health resources from low quality health resources on the Internet & 3.138 & 1.130 & 3 \\
I feel confident in using information from the Internet to make health decisions & 3.150 & 1.030 & 3 \\
\hline
\end{tabular}

Differences in the internet using for decision-making, the capability to discriminate between reliable and unreliable resources of online health information and the self-confidence to use the online information to make health decisions were assessed between the two genders using MannWhitney's test. The results demonstrated that though men obtained lower mean scores than women in the noted items, the difference among them was not statistically meaningful (Table 3). 
The difference in mean score of the importance of access to eHealth information between the two genders was also assessed by Mann-Whitney test and the results showed that the average score of men $(1.2042 .87)$ was lower than women $(1.091 \pm 3.25)$ and this result was statistically significant $(\mathrm{z}=-1.98$, $\mathrm{p}$-value $=0.048)$.

Table 3: The importance of access to eHealth information and the use of the internet for decision-making by gender

\begin{tabular}{lccc}
\hline \multicolumn{1}{c}{ Variable } & \multicolumn{1}{c}{$\begin{array}{c}\text { Mean score } \pm \text { Std. } \\
\text { Median }\end{array}$} & P-Value \\
\cline { 2 - 3 } & Female & Male & 0.048 \\
\hline The importance of access to eHealth information & $3.25 \pm 1.091$ & $2.87 \pm 1.204$ & 3 \\
& 3 & $3.30 \pm 1.418$ & 0.498 \\
The usefulness of the internet in decision-making & $3.52 \pm 1.190$ & 4 & 0.912 \\
$\begin{array}{l}\text { The ability to differentiate between reliable and unreliable } \\
\text { online health information resources }\end{array}$ & $3.14 \pm 1.069$ & $3.13 \pm 1.231$ \\
$\begin{array}{l}\text { Self-confidence in using information from the internet for } \\
\text { medical and health decision-making }\end{array}$ & $3.23 \pm 0.967$ & $3.02 \pm 1.118$ \\
\end{tabular}

The results of the one-way ANOVA showed a significant difference between the different education groups by eHealth literacy level $(\mathrm{F}=5.224 ; \mathrm{P}=0.001)$. The Scheffe post-hoc test was used to follow-up on the differences between the education groups. Its results demonstrated that the mean eHealth literacy score was significantly lower in the high school dropout group (23.04 \pm 7.69$)$ compared to the high school graduate group $(28.01 \pm 10.62 ; \mathrm{P}=0.03)$ and the group with a bachelor's degree $(30.93 \pm 5.60 ; \mathrm{P}=0.02)$.

Furthermore, the Kruskal-Wallis test results revealed the significant differences between the different education groups in terms of the importance of access to eHealth information, the ability to differentiate reliable and unreliable online health information resources and the self-confidence in using the information available on the internet to make health decisions (Table 4). 
Table 4: The eHealth literacy level, importance of internet access, ability to differentiate and self-confidence to use the information available on the internet based on participants' education level

\begin{tabular}{|c|c|c|c|c|c|c|}
\hline \multirow{2}{*}{ Variable } & \multicolumn{5}{|c|}{$\begin{array}{c}\text { Mean score } \pm \text { Std. } \\
\text { Median }\end{array}$} & \multirow{2}{*}{$\begin{array}{c}\text { P- } \\
\text { Value }\end{array}$} \\
\hline & $\begin{array}{l}\text { High school } \\
\text { dropout }\end{array}$ & $\begin{array}{l}\text { High school } \\
\text { graduate }\end{array}$ & $\begin{array}{c}\text { Associates } \\
\text { degree }\end{array}$ & $\begin{array}{c}\text { Bachelor's } \\
\text { degree }\end{array}$ & $\begin{array}{c}\text { Master's } \\
\text { degree }\end{array}$ & \\
\hline eHealth literacy level & $\begin{array}{c}23.04 \pm 7.696 \\
22\end{array}$ & $\begin{array}{c}28.02 \pm 10.623 \\
28\end{array}$ & $\begin{array}{c}27.67 \pm 4.899 \\
28\end{array}$ & $\begin{array}{c}30.94 \pm 5.603 \\
32\end{array}$ & $\begin{array}{c}36.00 \pm 5.657 \\
36\end{array}$ & 0.001 \\
\hline $\begin{array}{l}\text { The importance of } \\
\text { access to eHealth } \\
\text { information }\end{array}$ & $\begin{array}{c}3.28 \pm 3.765 \\
3\end{array}$ & $\begin{array}{c}3.19 \pm 1.093 \\
3\end{array}$ & $\begin{array}{c}3.17 \pm 0.985 \\
3\end{array}$ & $\begin{array}{c}3.69 \pm 1.138 \\
4\end{array}$ & $\begin{array}{c}4.50 \pm 0.707 \\
4\end{array}$ & 0.034 \\
\hline $\begin{array}{l}\text { The usefulness of the } \\
\text { internet in decision- } \\
\text { making }\end{array}$ & $\begin{array}{c}3.24 \pm 1.325 \\
3\end{array}$ & $\begin{array}{c}3.55 \pm 1.280 \\
4\end{array}$ & $\begin{array}{c}3.50 \pm 1.383 \\
4\end{array}$ & $\begin{array}{c}3.63 \pm 0.885 \\
4\end{array}$ & $\begin{array}{c}5.00 \pm 0.00 \\
5\end{array}$ & 0.144 \\
\hline $\begin{array}{l}\text { The ability to } \\
\text { differentiate between } \\
\text { reliable and } \\
\text { unreliable online } \\
\text { health information } \\
\text { resources }\end{array}$ & $\begin{array}{c}2.87 \pm 1.218 \\
3\end{array}$ & $\begin{array}{c}3.21 \pm 1.044 \\
3\end{array}$ & $\begin{array}{c}3.28 \pm 0.958 \\
3\end{array}$ & $\begin{array}{c}3.75 \pm 0.856 \\
4\end{array}$ & $\begin{array}{c}4.50 \pm 0.707 \\
4\end{array}$ & 0.016 \\
\hline $\begin{array}{l}\text { Self-confidence in } \\
\text { using information } \\
\text { from the internet for } \\
\text { medical and health } \\
\text { decision-making }\end{array}$ & $\begin{array}{c}2.93 \pm 0.990 \\
3\end{array}$ & $\begin{array}{c}3.13 \pm 1.057 \\
3\end{array}$ & $\begin{array}{c}3.11 \pm 0.900 \\
3\end{array}$ & $\begin{array}{c}4.06 \pm 0.860 \\
4\end{array}$ & $\begin{array}{c}4.50 \pm 0.707 \\
4\end{array}$ & $<0.001$ \\
\hline
\end{tabular}

The independent t-test was used to calculate the mean eHealth literacy score in both the age group above 40 and the group aged 40 and less. The results showed that the mean eHealth literacy level in the group aged 40 and less was significantly higher (8.336 \pm 28.896$)$ compared to the group above 40 age (7.212 \pm 20.796$) ;(t=6.074 ; \mathrm{P}<0.001)$.

\section{Discussion}

The eHealth literacy impact on the health outcomes have been confirmed in several researches. Knowledgeable people make better use of the medical facilities available to them and less frequently request medical tests [39]. A good knowledge about health and make better efforts to identify and perform screening tests, is probably associated with high level of eHealth literacy [40].

Given that family caregivers have a major role in ensuring the provision of health services to the elderly, the current research was conducted to evaluate eHealth literacy in the family caregivers of the elderly with hypertension and type-II diabetes. 
The current results demonstrated that family caregivers have a poor level of eHealth literacy (Table 4). A poor level of eHealth literacy was also reported in similar studies conducted on different groups, including the students [22] and patients referring to a military hospital [41]. Nonetheless, a study conducted on dental patients showed a good level of eHealth literacy among this group [26]. Further studies on different groups of the population are thus necessary.

The present findings also showed that the caregivers of the elderly have deficiencies in differentiating quality health information from poor-quality and their use to make decisions, which is the main factor involved in the poor eHealth literacy of the study population (Table 2). This result concurs with the results obtained in studies by Park [21], Dashti [22] and Tubaishat [42] as well as many other studies $[21,43]$. Since the family caregivers of the elderly use the internet to obtain health information, it is essential for this group to acquire the necessary knowledge about searching and assessing online health information, so that the risks of using incorrect medical information can be eliminated, because using incorrect information may increase the economic burden on the patients and health systems. It is also necessary for health professionals to raise elderly caregivers' knowledge and help them in identifying reliable information sources. Experts should also introduce websites containing quality health-related information to caregivers, so that they can use the information provided through reliable and quality websites to provide the elderly with care services.

The present study also showed that access to eHealth information is more important for family caregivers with a higher eHealth literacy, which may be due to their higher skills in obtaining health and medical information from the internet. Such an approach, and people's increasing dayto-day need to use the internet, especially in the health sector, necessitate experts' adoption of strategies to improve the access to the internet.

\section{The relationship between the study variables and eHealth literacy in the family caregivers of the elderly:}

This part of the study presents the factors related to eHealth literacy in the family caregivers of the elderly with hypertension and type-II diabetes. Variables including age, gender and education were assessed in this study.

The present research revealed a significant relationship between age and the eHealth literacy level, such that the group above 40 age had lower eHealth literacy compared to the group aged 40 and less. This finding may be since compared to middle adults, access to digital media is easier for young adults and they are more experienced in surfing the internet (7). This finding are in line with a study results on eHealth literacy level of Greek citizens as well as the results of a study on eHealth literacy of dental patients [26,44]; however, some other studies did not find this relationship to be significant $[21,42]$. According to the present findings, further studies are required to ascertain the relationship between age and eHealth literacy. Hence, while advising the caregivers to use the Internet, their age (especially in the case of the age group above 40 age) should be considered and encourage them to consult the elderly physicians before using e-health information to make decision on elderlies' health. It does not emphasize that direct education for the elderly should be ignored; instead, elderly people should be encouraged to speak with their caregivers about electronic health information and use this information. 
As for participants' gender, the present study showed that although female caregivers had higher eHealth literacy scores than male caregivers, the difference among them was not statistically significant, which agrees with the results obtained by Park et al. [21].

The present study also revealed that using the internet to make health-related decisions was more important to women than men, but it was not statistically significant (Table 3). Furthermore, difference among the gender groups in terms of "the importance of access to eHealth information" was statistically significant (Table 3). It demonstrates that access to internet is more important for women rather than men. It should be noted that more studies are needed to ascertain the relationship between gender and their tendency to apprise health information in decision making. Given this importance and regarding that women have a greater role in searching for health-related information [21], the female caregivers of the elderly ought to receive more training on how to search for information and its proper use. Moreover, since women tend to prioritize the needs of other family members over their own and have a greater tendency to give care and assume responsibility [45], women's role should be particularly emphasized in planning elderly care.

The current research showed a significant relationship among the different education groups by the eHealth literacy level (Table 4). The higher eHealth literacy level was associated with higher education level. This finding is in line with the finding of a study on baby boomers and older adults [46].

As expected, in this study, people with higher education levels were better able to differentiate quality from poor-quality health information sources (Table 4), which concurs with the results of other studies $[42,43,47]$. In a study conducted by Hanik et al. on master's degree students, the senior students had a higher eHealth literacy compared to the first-year students, which confirms the positive effect of education on eHealth literacy [48]. Electronic Health literacy level therefore seems to be associated with the level of education. Caregivers' education level should therefore be considered when advising them to use online health information and when giving instructions on the proper use of this information. It should be noted that the result of this study is based on selfreport abilities and further research is needed to understand the actual ehealth literacy skills of caregivers and its correlation with education level.

The relevant health and medical organizations should take actions such as providing infographics on searching for health information and introducing books on how to search for information on the internet as well as introducing reliable websites to caregivers so that they can provide the elderly with health services and thus improve their quality of care.

\section{Conclusions}

The present study showed that the family caregivers of the elderly had a poor level of eHealth literacy. Since, in the modern times, health information technology is expanding, eHealth literacy is regarded as a very important part of health literacy. Identifying and evaluating the level of eHealth literacy in the family caregivers of the elderly may be an effective measure in advancing the strategies for improving the quality of life of the elderly. Moreover, eHealth literacy can increase family caregivers' ability to access information about common old-age diseases such as hypertension and type-II diabetes and enable them to manage the challenges of daily living 
experienced by the elderly. Experts also believe that one of the practical strategies that family caregivers, especially children, can employ to help the elderly with chronic diseases is to provide them with information, which can enhance the independence and quality of life of the elderly [49]. The authorities in charge of elderly health are therefore recommended to familiarize caregivers with proper ways of using online health information. So that both the elderly and their families may reap some benefits, including improved care conditions and savings in terms of treatment costs and time.

\section{Limitations}

The present study had a number of limitations. First, it was conducted in one of the health centers in the province of Tehran; conducting the same study in other centers is likely to present different results. In addition, the present study used eHEALS, which is a questionnaire that determines participants' eHealth literacy through self-reporting, and the respondents' actual performance may have differed from their self-reported skills. Finally, conducting the same type of study in other cities with larger sample sizes can complement the present findings.

\section{Conflicts of Interests}

No conflicts of interest.

\section{Acknowledgements}

This study is related to the project NO. 1397/44121 from Student Research Committee, Shahid Beheshti University of Medical Sciences, Tehran, Iran.

We also appreciate the "Student Research Committee" and "Research \& Technology Chancellor" in Shahid Beheshti University of Medical Sciences for their financial support of this study.

\section{References}

1. Vokonas PS, Kannel WB, Cupples LA. 1988. Epidemiology and risk of hypertension in the elderly: the Framingham Study. J Hypertens Suppl. 6(1), S3-9. PubMed

2. Brunner LS. Brunner \& Suddarth's textbook of medical-surgical nursing. Vol. 1. Lippincott Williams \& Wilkins; 2010.

3. Stats A. Federal Interagency Forum on Aging Related Statistics. Retrieved online April. 2006;22:2009.

4. Kim Y, Schulz R. 2008. Family caregivers' strains: comparative analysis of cancer caregiving with dementia, diabetes, and frail elderly caregiving. J Aging Health. 20(5), 483503. PubMed https://doi.org/10.1177/0898264308317533 
5. Chae CU, Pfeffer MA, Glynn RJ, Mitchell GF, Taylor JO, et al. 1999. Increased pulse pressure and risk of heart failure in the elderly. JAMA. 281(7), 634-639. PubMed https://doi.org/10.1001/jama.281.7.634

6. Barrett-Connor E, Suarez L, Khaw K, Criqui MH, Wingard DL. 1984. Ischemic heart disease risk factors after age 50. J Chronic Dis. 37(12), 903-08. PubMed https://doi.org/10.1016/0021-9681(84)90066-3

7. Wee H-L, Cheung Y-B, Li S-C, Fong K-Y, Thumboo J. 2005. The impact of diabetes mellitus and other chronic medical conditions on health-related Quality of Life: Is the whole greater than the sum of its parts? Health Qual Life Outcomes. 3(1), 2. PubMed https://doi.org/10.1186/1477-7525-3-2

8. Leahy MJ, Thurber D, Calvert JF. 2005. Benefits and challenges of research with the oldest old for participants and nurses. Geriatr Nurs. 26(1), 21-28. PubMed https://doi.org/10.1016/j.gerinurse.2004.11.016

9. C.H. G, S.E. E, M. L, H.P. H, Garcia CH, Espinoza SE, et al. Health literacy associations between Hispanic elderly patients and their caregivers. J Health Commun. 2013;18 Suppl 1(sup1):256-72.

10. Etters L, Goodall D, Harrison BE. 2008. Caregiver burden among dementia patient caregivers: a review of the literature [Internet]. J Am Acad Nurse Pract. 20(8), 423-28. https://search.proquest.com/docview/212892032?accountid=14472\%0Ahttp://resolver.ebsco host.com/openurl?ctx_ver=Z39.88-2004\&ctx_enc=info:ofi/enc:UTF-

8\&rfr_id=info:sid/ProQ\%3Anahs\&rft_val_fmt=info:ofi/fmt:kev:mtx:journal\&rft.genre=arti cle\&rft.jtitle=Journal+. PubMed https://doi.org/10.1111/j.1745-7599.2008.00342.x

11. Amanian MF. MA. H. The Effect of the Training Program about Management of Elders' Common Problems on the Level of Job Stress in Caregivers of Nursing Homes. J Res Dev Nurs Midwifery [Internet]. 2013; Available from: http://goums.ac.ir/jgbfnm/article-1-456en.pdf

12. Lam L, Lam M. 2009. The use of information technology and mental health among older care-givers in Australia [Internet]. Aging Ment Health. 13(4), 557-62. doi:. PubMed https://doi.org/10.1080/13607860802607306

13. Kim H. 2015. Understanding Internet Use Among Dementia Caregivers: Results of Secondary Data Analysis Using the US Caregiver Survey Data [Internet]. Interact J Med Res. 4(1), e1. http://www.i-jmr.org/2015/1/e1/. PubMed https://doi.org/10.2196/ijmr.3127

14. Mitsutake S, Shibata A, Ishii K, Okazaki K, Oka K. 2011. Developing Japanese version of the eHealth literacy scale (eHEALS). Nippon Koshu Eisei Zasshi. 58(5), 361-71. PubMed

15. Norman CD, Skinner HA. 2006. eHEALS: The eHealth Literacy Scale. J Med Internet Res. 8(4):e27. PubMed https://doi.org/10.2196/jmir.8.4.e27 
16. Welch JL, Siek KA, Connelly KH, Astroth KS, McManus MS, et al. 2010. Merging health literacy with computer technology: Self-managing diet and fluid intake among adult hemodialysis patients. Patient Educ Couns. 79(2), 192-98. PubMed https://doi.org/10.1016/j.pec.2009.08.016

17. Norman CD, Skinner HA. 2006. eHealth literacy: essential skills for consumer health in a networked world. J Med Internet Res. 8(2), e9. PubMed https://doi.org/10.2196/jmir.8.2.e9

18. Witten NAK, Humphry J. 2018. The Electronic Health Literacy and Utilization of Technology for Health in a Remote Hawaiian Community: Lana 'i. Hawaii J Med Public Health. 77(3), 51. PubMed

19. Jones S, Johnson-Yale C, Millermaier S, Perez FS. 2009. Everyday life, online: US college students' use of the Internet. First Monday. 14(10). https://doi.org/10.5210/fm.v14i10.2649

20. Pagliari C, Sloan D, Gregor P, Sullivan F, Detmer D, et al. 2005. What is eHealth (4): a scoping exercise to map the field. J Med Internet Res. 7(1):e9. PubMed https://doi.org/10.2196/jmir.7.1.e9

21. Park H, Cormier E, Gordon G, Baeg JH. 2016. Identifying Health Consumers' eHealth Literacy to Decrease Disparities in Accessing eHealth Information. Comput Informatics. Comput Inform Nurs. 34(2), 71-76. PubMed https://doi.org/10.1097/CIN.0000000000000205

22. Dashti S, Peyman N, Tajfard M, Esmaeeli H. 2017. E-Health literacy of medical and health sciences university students in Mashhad, Iran in 2016: a pilot study. Electron Physician. 9(3), 3966. PubMed https://doi.org/10.19082/3966

23. Hamzehei R, Ansari M, Rahmatizadeh S, Valizadeh-Haghi S. 2018. Websites as a tool for public health education: determining the trustworthiness of health websites on Ebola disease. Online J Public Health Inform. 10(3):e221. PubMed https://doi.org/10.5210/ojphi.v10i3.9544

24. Valizadeh-Haghi S, Rahmatizadeh S. 2018. Evaluation of the Quality and Accessibility of Available Websites on Kidney Transplantation. Urol J. 15(5):261-265 PubMed

25. Rahmatizadeh S, Valizadeh-Haghi S. Evaluating the trustworthiness of consumer-oriented health websites on diabetes. Libr Philos Pract. 2018

26. Valizadeh-Haghi S, Rahmatizadeh S. 2018. eHealth literacy and general interest in using online Health information: a survey among patients with dental diseases. Online J Public Health Inform. 10(3):e219. PubMed https://doi.org/10.5210/ojphi.v10i3.9487

27. Knapp C, Madden V, Wang H, Sloyer P, Shenkman E. 2011. Internet use and eHealth literacy of low-income parents whose children have special health care needs. J Med Internet Res. 13(3):e75. PubMed https://doi.org/10.2196/jmir.1697 
28. Baker L, Wagner TH, Singer S, Bundorf MK. 2003. Use of the Internet and e-mail for health care information: results from a national survey. JAMA. 289(18), 2400-06. PubMed https://doi.org/10.1001/jama.289.18.2400

29. Cimino JJ, Patel VL, Kushniruk AW. 2002. The patient clinical information system (PatCIS): technical solutions for and experience with giving patients access to their electronic medical records. Int J Med Inform. 68(1-3), 113-27. PubMed https://doi.org/10.1016/S1386-5056(02)00070-9

30. Noroozian M. 2012. The elderly population in Iran: An ever growing concern in the health system. Iran J Psychiatry Behav Sci. 6(2), 1-6. PubMed

31. Cheraghi MA, Payne S, Salsali M. 2005. Spiritual aspects of end-of-life care for Muslim patients: experiences from Iran. Int J Palliat Nurs. 11(9), 468-74. PubMed https://doi.org/10.12968/ijpn.2005.11.9.19781

32. Efthymiou A, Middleton N, Charalambous A, Papastavrou E. 2017. The Association of Health Literacy and Electronic Health Literacy With Self-Efficacy, Coping, and Caregiving Perceptions Among Carers of People With Dementia: Research Protocol for a Descriptive Correlational Study. JMIR Res Protoc. 6(11), e221. PubMed https://doi.org/10.2196/resprot.8080

33. Pinto E. 2007. Blood pressure and ageing. Postgrad Med J. 83, 109-14. PubMed https://doi.org/10.1136/pgmj.2006.048371

34. Tran BNN, Singh M, Singhal D, Rudd R, Lee BT. 2017. Readability, complexity, and suitability of online resources for mastectomy and lumpectomy [Internet]. J Surg Res. 212, 214-21. doi:. PubMed https://doi.org/10.1016/j.jss.2017.01.012

35. Kinnane NA, Milne DJ. 2010. The role of the Internet in supporting and informing carers of people with cancer: a literature review [Internet]. Support Care Cancer. 18(9), 1123-36. doi:. PubMed https://doi.org/10.1007/s00520-010-0863-4

36. Sana JDL, Martha S, eds. Encyclopedia of Aging and Public Health. Springer; 2008.

37. van der Vaart R, van Deursen AJAM, Drossaert CHC, Taal E, van Dijk JAMG, et al. 2011. Does the eHealth Literacy Scale (eHEALS) measure what it intends to measure? Validation of a Dutch version of the eHEALS in two adult populations. J Med Internet Res. 13(4), e86. PubMed https://doi.org/10.2196/jmir.1840

38. Bazm S, Mirzaei M, Fallahzadeh H, Bazm R. 2016. Validity and Reliability of the Iranian Version of eHealth Literacy Scale. Journals Community Heal Res. 5(2), 121-30.

39. Macias W, Lewis LS, Shankar V. 2004. Dr. Mom and Dr [Web] [Internet]. J Interact Advert. 4(2), 9-19. doi:. https://doi.org/10.1080/15252019.2004.10722083 
40. Mitsutake S, Shibata A, Ishii K, Oka K. 2012. Association of ehealth literacy with colorectal cancer knowledge and screening practice among internet users in Japan. J Med Internet Res. 14(6) : e153. PubMed https://doi.org/10.2196/jmir.1927

41. Tadayon H, Abbasi M, Rasouli HR. 2018. Evaluation of e-health literacy and its predictor factors among patients referred to a military hospital in Tehran, Iran, 2017. J Mil Med. 20(1), 83-92.

42. Tubaishat A, Habiballah L. 2016. eHealth literacy among undergraduate nursing students [Internet]. Nurse Educ Today. 42, 47-52. doi:. https://doi.org/10.1016/j.nedt.2016.04.003

43. Park H, Lee E. 2015. Self-reported eHealth literacy among undergraduate nursing students in South Korea: A pilot study. Nurse Educ Today. 35(2), 408-13. PubMed https://doi.org/10.1016/j.nedt.2014.10.022

44. Xesfingi S, Vozikis A. 2016. eHealth Literacy: In the Quest of the Contributing Factors. Interact J Med Res. 5(2), e16. PubMed https://doi.org/10.2196/ijmr.4749

45. Eagly AH, Steffen VJ. 1986. Gender and aggressive behavior: a meta-analytic review of the social psychological literature. Psychol Bull. 100(3), 309. PubMed https://doi.org/10.1037/0033-2909.100.3.309

46. Tennant B, Stellefson M, Dodd V, Chaney B, Chaney D, et al. 2015. eHealth literacy and Web 2.0 health information seeking behaviors among baby boomers and older adults. $J$ Med Internet Res. 17(3), e70. PubMed https://doi.org/10.2196/jmir.3992

47. Stellefson M, Hanik B, Chaney B, Chaney D, Tennant B, Chavarria EA. 2011. eHealth Literacy Among College Students: A Systematic Review With Implications for eHealth Education. J Med Internet Res. 13(4), e102. PubMed https://doi.org/10.2196/jmir.1703

48. Hanik B, Stellefson M. 2011. E-Health Literacy Competencies among Undergraduate Health Education Students : A Preliminary Study. Int Electron J Health Educ. 14, 46-58.

49. Common Chronic Conditions of the Elderly | Elderly and Chronic Conditions [Internet]. Parentgiving. 2019 [cited 2019 Jan 28]. Available from: https://www.parentgiving.com/elder-care/common-chronic-conditions-and-aging-at-home/ 